\title{
Feline heartworm (Dirofilaria immitis) infection: first case report of serological diagnosis in Brazil, confirmed by molecular assay
}

\section{BARBARA B. PEREIRA, BETHÂNIA F. BASTOS, LUCAS KEIDEL, DANIELA LELES and BEATRIZ BRENER}

\author{
Departamento de Microbiologia e Parasitologia, Universidade Federal Fluminense, Rua
} Professor Hernani Melo, 101, São Domingos, 24210-130 Niterói, RJ, Brazil

Manuscript received on January 30, 2017; accepted for publication on June 28, 2017

\begin{abstract}
The clinical importance of heartworm infection in cats has indeed increased in recent years. Dirofilaria immitis infection has been reported worldwide in cats and continues to be regularly diagnosed in endemic areas. The diagnosis can be overlooked easily, especially in Brazil, where there is not a specific feline immunodiagnostic test, forcing the veterinarians to use a test made for the canine host. In 2015, a 10 -year-old female neutered cat was diagnosed with D. immitis using an antigen serological test, based on imunocromatography and designed for dogs. The modified Knott test was negative. As the disease progressed, the cat showed clinical signals of respiratory distress, such as dyspnoea and polypnea in addition to prostration and emaciation, and died a few weeks after the diagnosis. During necropsy, one adult nematode was found in the pulmonary artery. D. immitis infection was confirmed by molecular amplification, performed in the worm fragment. This is the first report of serological diagnosis of feline dirofilariasis in Brazil. A chemoprophylaxis routine in cats should be done, as is done in dogs from endemic areas.
\end{abstract}

Key words: cat, parasite, dirofilariasis, immunodiagnosis.

\section{INTRODUCTION}

Dirofilariasis (heartworm disease) is caused by the filarial nematode Dirofilaria immitis, distributed worldwide, primarily affecting dogs and cats (Jones et al. 2014). Different species of culicid mosquitoes belonging to the genera Culex, Aedes and Anopheles have been implicated in the transmission of this parasite (Simon et al. 2012). Studies suggest that the main vectors of dirofilariasis in Rio de Janeiro

Correspondence to: Beatriz Brener

E-mail: brener@vm.uff.br

* Contribution to the centenary of the Brazilian Academy of Sciences. were Aedes scapularis, Aedes aeniorhynchus and Culex quinquefasciatus (Labarthe et al. 1998).

Cats are less easily infected with heartworms than dogs. Clinically affected cats may present subclinically infected or chronic respiratory signs and acute death (Atkins et al. 2008). Also, in cases of pulmonary larval dirofilariasis, infected cats can have a Heartworm Associated Respiratory Disease (HARD), that is associated with asthmalike clinical signs (Venco et al. 2011).

Cats are inherently resistant to heartworm infection. This is reflected by relatively low adult worm burden, the lack of microfilaraemia and their 
short life span, which complicates the diagnosis of this disease in the feline patient (Lee and Atkins 2010).

Dirofilariasis is usually diagnosed by detection of the microfilariae in the peripheral blood, immunological tests and molecular approaches (Jones et al. 2014).

For cats, performing a modified Knott test for microfilariae is rarely fruitful because patency is short lived. However, when present, microfilaraemia provides a definitive diagnosis (Jones et al. 2014).

Antibody tests have the advantage of being able to detect infection by both male and female worms, as larvae of either sex can stimulate a detectable immune response as early as two months post infection. On the other hand, a positive antibody test result only indicates exposure to heartworms and not necessarily a current infection (Simon et al. 2012, Jones et al. 2014).

The antigen test detects a protein that is found primarily in the reproductive tract of the female worm. This test may lack sensitivity due to low number of worms and the possibility of infection caused only by male worms. However, the rate of false-positive results with antigen serology is low, so that a positive result generally indicates a current infection (Snyder et al. 2000).

Several different molecular protocols have been developed during the last few years, including single species identification using species-specific PCR (Polymerase Chain Reaction) assays, or simultaneous detection of the different Dirofilaria species using multiplex PCR and PCR-RFLP (Restriction Fragment Length Polymorphism) assays (Nuchprayoon et al. 2006).

The prevalence of feline heartworm infection, less well defined because definitive antemortem diagnosis is difficult to achieve, is generally estimated to be $5 \%$ to $20 \%$ that of the canine population in the same area (Venco et al. 2011).

The present communication describes the first case report of serological diagnosis of feline dirofilariasis in Brazil, confirmed by molecular assay.

\section{CASE DESCRIPTION}

A female cat was included in a study that aimed to establish the seroprevalence of heartworm infection in cats in the Oceanic Area of Niterói city, Rio de Janeiro, Brazil, an endemic area for canine dirofilariasis. The study was approved by the Committee of Animal Use (CEUA) of the Universidade Federal Fluminense.

In the date of the collection of the blood sample, the cat was not presenting any signs of disease. The blood sample was submited to the Knott test and to an antigen test based on imunocromatography and designed for dogs (Alere ${ }^{\circledR}$ ), according to manufacturer's instructions. The Knott test was negative and the result of the immunological test was positive.

The positive cat was female, neutered, domestic short hair, with 10 years old. Some weeks after the collection of the blood sample, the cat started to present some clinical signs, like prostration, dyspnoea, polypnea and emaciation.

The blood sample was submitted to the PCR assay, but the DNA of the parasite was not amplified probably because the patient was not microfilaremic.

The positive cat lived in a house with more six cats and six dogs. All cats were tested by using the modified Knott test and the antigen test and none of those was positive. The contacting dogs were tested by the modified Knott test and five (5/6) dogs presented microfilariaes.

The patient died two months after the diagnosis. The necropsy showed one female filarial nematode, measuring $27.5 \mathrm{~cm}$ in length in pulmonary artery (Figures 1 and 2).

The adult parasite was submitted to a molecular assay, using the targed cox 1 and 12 $\mathrm{S}$. The result confirmed that the parasite was $D$. 


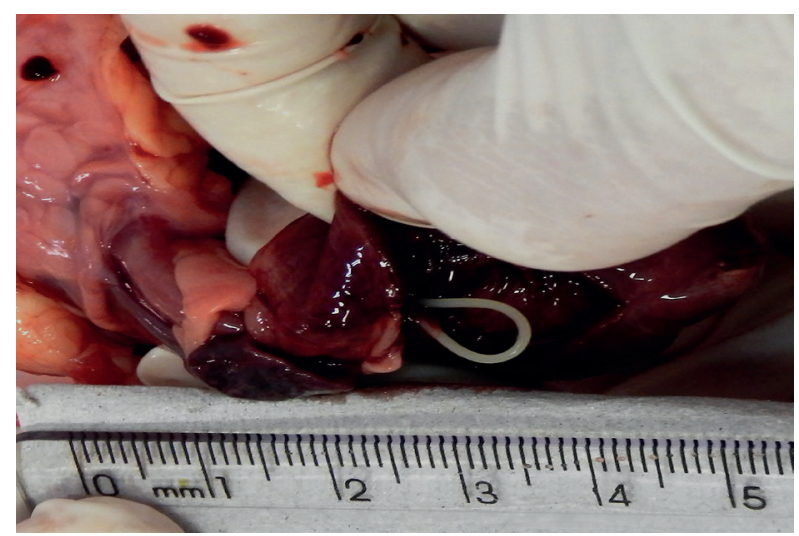

Figure 1 - Necropsy of a feline, showing a filarial nematode in the pulmonary artery.

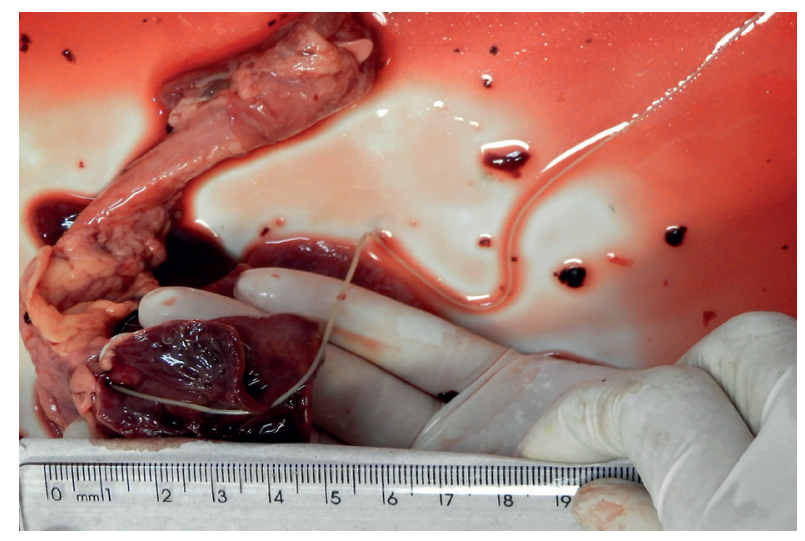

Figure 2 - Necropsy of a feline, showing a filarial nematode in the pulmonary artery, measuring $27.5 \mathrm{~cm}$ in length.

immitis, presenting $99 \%$ of similarity with the genetic sequencing deposited in Genbank (Figure 3).

\section{DISCUSSION}

Some authors believe that the feline infection is likely to occur anywhere the nematode parasite is found in dogs (Nelson 2008). On the other hand, other researches believe that the infection in cats is related with the presence and abundance of the vectors, the culicid mosquitoes (Magi et al. 2002). No matter what is the main factor to occur the feline infection, brazilian researches showed that, in the studied area, there are many potential vectors (Labarthe et al. 1998) and studies revealed a seroprevalence of $58.6 \%$ in a dog population of the same area (Labarthe et al. 2014). Therefore, this location presents both factors to explain the occurrence of the feline infection.

In 2008, the antigen test for D. immitis was incorporated into the kit for serologic test of FIV and FeLV, by the IDEXX Laboratories. This test, commonly used in clinical routine cats, highlights the need for diagnosis of this disease, as its importance in the feline population. The kit is available in the United States, some European countries and Australia.

In the absence of specific feline diagnostic tests for $D$. immitis in Brazil, we used an immunoassay for antigen test, made for the canine host $\left(\right.$ Alere $\left.^{\circledR}\right)$. According to the manufacturer, the test was able to detect the antigen, even if there was only one female adult parasite in the host.

In this study, the sample was positive in the immunoassay. Despite the immunochromatographic kit being suitable for dogs, the test was able to detect infection in the feline host, confirming the sensitivity. In the necropsy, we only found one female parasite in the pulmonary tract.

Researchers compare the results of diagnostic tests available in the United States and from different manufacturers, which detect $D$. immitis infection (Berdoulay et al. 2004). In such results, cats were positive in kits made for the feline species, and also had a positive result in tests targeted to the canine host. Comparing these results and the finding in our present study, apparently the fact that the host be canine or feline is indifferent to test sensitivity to antigen test.

There was no amplification by PCR in the blood sample that tested positive in the immunoassay, despite the cat having a female adult parasite in the pulmonary artery. This finding can be explained due to the absence of circulating parasite DNA because the host did not have microfilaremia. The molecular test performed with the parasite obtained in the necropsy confirmed 


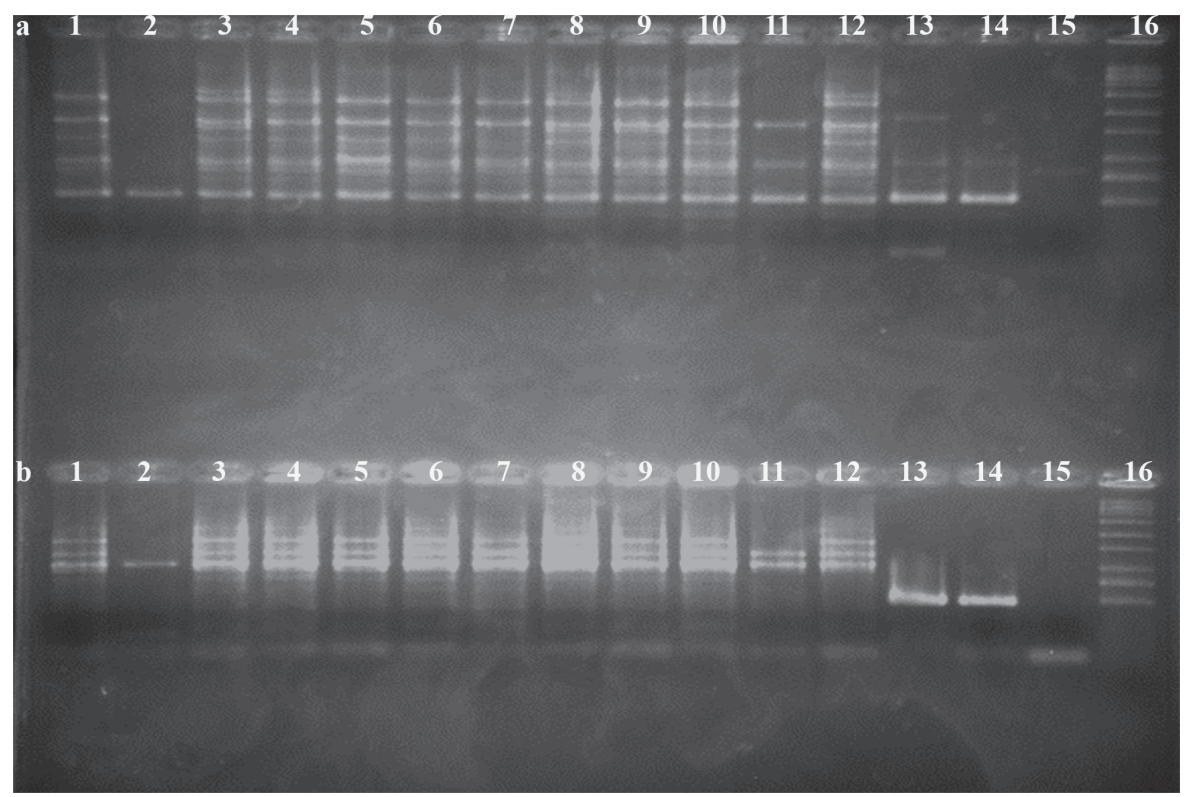

Figure 3 - Agarose gel electrophoresis (2\%). a) Mitochondrial cox1 DNA amplicom and b) 12S DNA amplicom. Lanes 1-12: blood samples. Lane 13: adult of Dirofilaria immitis from feline. Lane 14: positive control (adult of D. immitis from dog). Lane 15: negative control. Lane 16: $1 \mathrm{~kb}$ DNA Ladder (Ludwig Biotech).

that it was an adult of the nematode $D$. immitis. The Oceanic Area of Niterói is considered endemic for D. immitis infection (Labarthe et al. 2014), as we proved in the study. Therefore, chemoprophylaxis is needed in resident cats, as is done in dogs of endemic areas.

\section{ACKNOWLEDGMENTS}

The authors would like to acknowledge the support given by Coordenação de Aperfeiçoamento de Pessoal de Nível Superior (Capes), Conselho Nacional de Desenvolvimento Científico e Tecnológico (CNPq) and Pró-Reitoria de Pesquisa, Pós-Graduação e Inovação (PROPPI) of Universidade Federal Fluminense.

\section{REFERENCES}

ATKINS CE, ARTHER RG, CISZEWSKI DK, DAVIS WL, ENSLEY SM AND GUITY PS. 2008. Echocardiographic quantification of Dirofilaria immitis in experimentally infected cats. Vet Parasitol 158: 164-170.

BERDOULAY P, LEVI JK, SNYDER PS, PEGELOW MJ, HOOKS JL, TAVARES LM, GIBSON NM AND
SALUTE MC. 2004. Comparison of serological tests for the detection of natural heartworm infections in cats. J Am Anim Hosp Assoc 40: 376-384.

JONES S, GRAHAM W, SIMSON C, STANNARD R AND CARITHERS D. 2014. Current Feline guidelines for the Prevention, Diagnosis, and Management of Heartworm (Dirofilaria immitis) Infection in Cats. $<$ Available at https:/www.heartwormsociety.org/veterinary-resources/ american-heartworm-society-guidelines $>$ Accessed in Sep 05, 2016.

LABARTHE NV, PAIVA JP, REIFUR L, MENDES-DEALMEIDA F, MERLO A, PINTO CJC, JULIANI PS, ALMEIDA MAO AND ALVES LC. 2014. Updated canine infection rates for Dirofilaria immitis in areas of Brazil previously identified as having a high incidence of heartworm-infected dogs. Parasit Vectors 7: 493.

LABARTHE NV, SERRÃO ML, FONTENELE MYF, OLIVEIRA SJ AND LOURENÇO-DE-OLIVEIRA R. 1998. Potential vectors of Dirofilaria immitis (Leidy, 1856) in Itacoatiara, oceanic region of Niterói municipality State of Rio de Janeiro, Brazil. Mem Inst Oswaldo Cruz 93: 425-432.

LEE ACY AND ATKINS CE. 2010. Understanding feline heartworm infections: disease, diagnosis and treatment. Top Companion Anim Med 25: 4.

MAGI M, PRATI MC, SEBASTIANI B, BANDECCHI P AND GUBERTI V. 2002. Seroprevalence of feline heartworm disease in Tuscany. Vet Rec 3: 415-416. 
NELSON CT. 2008. Dirofilaria immitis in cats: diagnosis and management. Comp Cont Educ Pract Vet 30: 393-400.

NUCHPRAYOON S, JUNPEE A, NITHIUTHAI S, CHUNGPIVAT S, SUVANNADABBA S AND POOVORAWAN Y. 2006. Detection of filarial parasites in domestic cats by PCR-RFLP of ITS1. Vet Parasitol 140: 366-372.

SIMON F, SILES-LUCAS M, MORCHÓN R, GONZÁLEZMIGUEL J, MELLADO I, CARRETÓN E AND MONTOYA-ALONSO JA. 2012. Human and Animal
Dirofilariasis: the Emergence of a Zoonotic Mosaic. Clin Microbiol Ver 25: 507-544.

SNYDER PS, LEVY JK, SALUTE ME, GORMAN SP, KUBILIS PS, SMAIL PW AND GEORGE LL. 2000. Performance of serologic tests used to detect heartworm infection in cats. J Am Vet Med Assoc 216: 693-700.

VENCO L, GENCHI M, GENCHI C, GATTI D AND KRAMER L. 2011. Can heartworm prevalence in dogs be used as provisional data for assessing the prevalence of the infection in cats? Vet Parasitol 176: 300-303. 